\title{
Influence of the New Spanish Legislation concerning the Management of Nuclear Waste
}

\author{
B. Yolanda Moratilla Soria and Ainhoa Villar Lejarreta \\ Universidad P. Comillas, ETSI (ICAI), Cátedra Rafael Mariño de Nuevas Tecnologías Energéticas, C/ Alberto Aguilera 23 , \\ 28015 Madrid, Spain
}

Correspondence should be addressed to B. Yolanda Moratilla Soria; ymoratilla@upcomillas.es

Received 15 July 2013; Revised 24 September 2013; Accepted 25 September 2013

Academic Editor: Alejandro Clausse

Copyright (C) 2013 B. Y. Moratilla Soria and A. Villar Lejarreta. This is an open access article distributed under the Creative Commons Attribution License, which permits unrestricted use, distribution, and reproduction in any medium, provided the original work is properly cited.

\begin{abstract}
The aim of the present paper is to present and analyse the results obtained from a comparative economic feasibility study performed for the two main nuclear spent fuel management cycles: Once-Through Cycle and Twice-Through Cycle in a Spanish scenario, taking into account the new Spanish legislation with which new tax provisions for generation and storage of nuclear waste must be included in the cycle costs.
\end{abstract}

\section{Introduction}

Certainly, nuclear energy nowadays allows a constant covering of the electricity demand with stable and known prices while other forms of energy such as renewables do not ensure, at present, the stability of the power system since these are subject to external variables. Furthermore, petroleum suffers from continuous speculation and price fluctuations.

Moreover, nuclear energy makes a significant contribution to reducing pollutant emissions and allows a reduction in the country's dependence on foreign energy resources. Almost $15 \%$ of the world's electricity production comes from the nuclear sector. This percentage could be increased since, approximately, 65 new units are under construction in countries like Russia, South Korea, Japan, Finland, and France, along with emerging countries like China, India, and Bulgaria.

Focusing on Spain, 2011 has been an excellent year for nuclear energy production. The eight nuclear reactors under operation managed to produce $19,64 \%$ of the total electricity consumed in this country, becoming the source of energy with more operating hours and ranking as the second source in the supply of electricity to the Spanish power grid [1]. These results underline the importance of the Spanish nuclear power plants in the smooth functioning of the Spanish power system.
However, the main worldwide concern in relation to nuclear energy lies in providing an ultimate solution to nuclear spent fuel. No irrevocable decision has been yet made in any nuclear country regarding the final treatment given to radioactive waste, but there are two main streams that were currently put into practice in the industry. Nuclear spent fuel policies vary between the Once-Through Cycle (direct disposal) and the Twice-Through Cycle (reprocessing and recycling of the nuclear spent fuel).

In countries like Sweden and Finland, nuclear energy policies are determined to implement the Once-Through Cycle, and a great deal of research and several studies have been performed in the past with the objective of finding optimal sites for the geological repository needed in the direct disposal management option. In other countries with a history of reprocessing technology such as France and the United Kingdom, they not only have reprocessed their own spent fuel, clearly opting for the Twice-Through Cycle, but also have provided this nuclear fuel reprocessing service to countries lacking this technology as in the case of Holland and Spain, among others.

The divergence in the used fuel management policies of the nuclear countries is first of all clearly due to their history in nuclear technology and the current specificities within their nuclear park, as well as to the not always wellfocused governments' decisions regarding the subject. It is 
then when carrying out economic comparison studies of the main management, nuclear fuel cycles become an essential part when it comes to making a decision of which fuel cycle turns out to be the most adequate one. However, not only economic aspects should be taken into account. Key aspects like sustainability and optimal use of natural resources, along with future trends in technology developments and uncertainties surrounding fuel management in the OnceThrough Cycle, must be bared in mind in order to make the right choice for solving a complex technological and also social issue as the proper management of nuclear waste.

\section{State of the Art}

In this regard, many studies and papers have been carried out by international organizations in which economic aspects related to reprocessing costs and deep geological repository (DGR) costs have been analysed. The studies have been performed by the Massachusetts Institute of Technology (MIT) in 2003 [2] and 2011 [3], by the Boston Consulting Group (BCG) in 2006 [4], and by the Nuclear Energy Agency (NEA) for the Organization for Economic Co-operation and Development (OECD) in 1994 [5]. The main papers which analyse this subject are [6-13].

As an overall result, all the reports that have been studied conclude that the total management fuel cycle cost is slightly higher in the Twice-Through Cycle than in the Once-Through Cycle. This is due to the cost of reprocessing itself, which involves additional transport and maintenance, as well as a superior cost in managing recycled fuel elements, first in their fabrication phase, and furthermore once they have been irradiated, due to the higher radiotoxicity and decay heat.

However, according to the existing bibliography, despite of this higher cost in the Twice-Through Cycle, further developments of the existing technologies along with the high cost uncertainties surrounding the DGR costs could reverse the current relationship between both management cycle options.

Moreover, the possible implementation of future fast breeder reactors could also affect the cost relationship between the two fuel cycles mentioned, boosting fuel recycling processes in a worldwide scale since fast reactors are usually prepared to use plutonium as their basic fuel.

The paper "Recycling Versus Long Term Storage of Nuclear Fuel" [14] gathers together some economic results of previously published papers and analyses both the DGR costs and reprocessing costs in relation to the time frame in which each study was carried out.

According to this paper a significant increasing trend in time for the DGR cost can be drawn out from the multiple studies consulted. It is demonstrated that final nuclear waste disposal varies considerably from country to country as different reference scenarios are taken into account in their calculations; this is the case of the BCG report and the MIT report, which use Yucca Mountain as their reference scenario and differ from the European scenarios of both OECD studies [14]. This is showed in Figure 1.

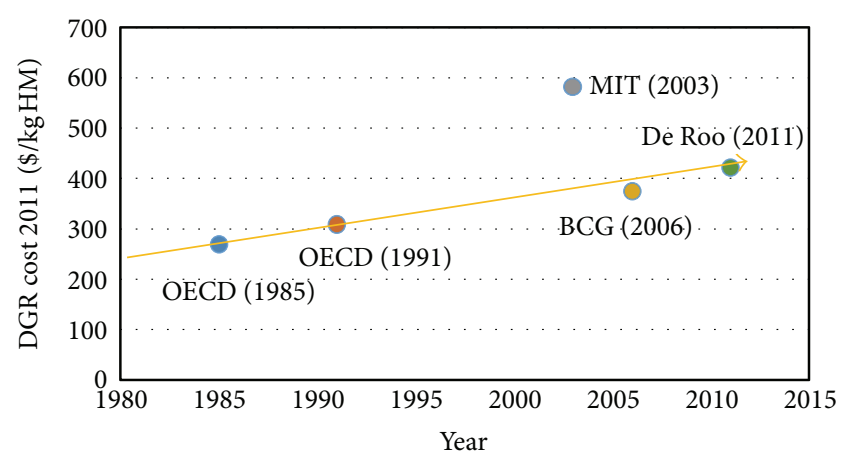

FIGURE 1: DGR costs trend [14].

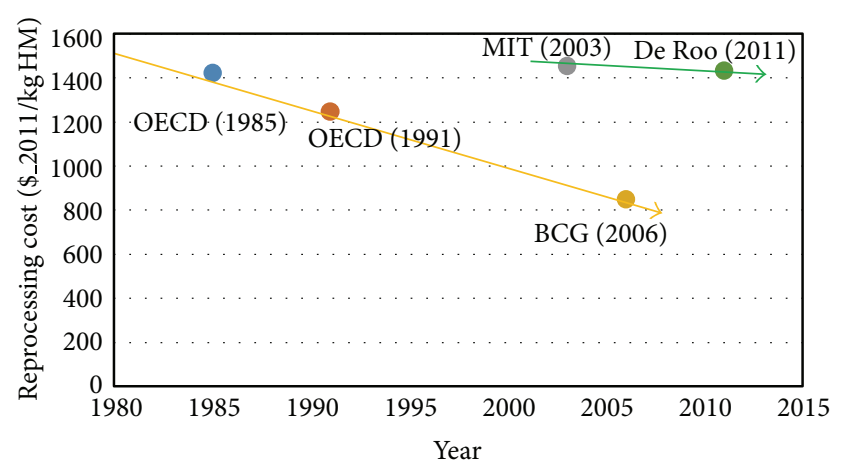

FIgURE 2: Reprocessing costs trend [14].

As to the reprocessing costs, a decreasing trend is expected with time, except for the MIT results, which are considered to be an outlier. This cost decrease is attributed to technical and economic improvements related to the processes involved in the fuel reprocessing industry. Experience gained in the sector has helped optimize costs. The same is believed that will happen with the DGR costs and its associated technologies in a longer term, as less cost uncertainties surround this management fuel cycle. This result is showed in Figure 2.

The aim of this paper is to display and analyse the results obtained from a comparative economic feasibility study performed for the two main nuclear spent fuel management cycles: Once-Through Cycle and Twice-Through Cycle in a Spanish scenario, considering the new Spanish legislation which introduces new taxes related to the nuclear radioactive waste and which will have more financial impact than what could be expected [15].

\section{Methodology Used for Fuel Cycle Costs Calculations}

The economic assessment consists of two parts. The first part of the study develops a cost analysis of the nuclear fuel management cycle for each option: Once-Through Cycle and Twice-Through Cycle, for the Spanish nuclear park. The second part carries out the specific economic feasibility assessment of the Spanish case. It dedicates a special interest 
to the impact of a new tax introduced in 2013 on production and interim storage of used nuclear fuel and radioactive waste.

The timeframe considered in the study covers the years from 2013 until 2028.

A methodology developed by the MIT [3] is chosen as a starting point to carry out the first part of the cost analysis. It is then modified to take into account the specific features of the Spanish scenario. For each management option, the frontend and back-end costs involved in the cycle are calculated as a previous result of the management unit cost, in $€ / \mathrm{kg}$ of fresh fuel introduced in the nuclear reactor. The methodology used ensures that a fair economical comparison is being carried out between the two management options.

In the case of the Once-Through Cycle, the costs considered in the total unit management cost calculation are first of all the ones related with the front-end of the fuel cycle:

(i) natural uranium purchase costs,

(ii) conversion and enrichment processes costs,

(iii) UOX fuel fabrication costs,

and secondly, the ones implied by the back-end of the fuel cycle, up to the considered date in the scope of our study (2028), that is, the interim storage costs of used fuel.

In the Twice-Through Cycle, apart from the costs of the front-end, additional costs such as spent fuel reprocessing, and new MOX fuel fabrication are taken into account.

As for the back-end costs, we consider only the interim storage of final high level waste generated by reprocessing. No interim storage of UOX or MOX spent fuel is considered, since the generated spent fuel during 2013-2028 is assumed to be sent to a reprocessing plant in order to subsequently sell the recovered plutonium and the reprocessed uranium in the international market. This is taken into account through a credit mechanism integrated in the reprocessing price.

Geological repository costs are not considered in any of the studied management cycles as this cost is surrounded by high uncertainties and falls outside the study's framework.

The second part of the study [15] carries out the specific economic feasibility assessment of the Spanish case. In the nuclear Spanish scenario, some key factors must be taken into account when studying both management options. These are

(i) the nuclear power plants' planned lifetime,

(ii) the spent fuel legacy currently stored in the nuclear power plants' pools,

(iii) the project for the Centralised Temporary Storage (CTS),

(iv) the entry into force, in 2013, of the Taxation Measures Law on Environmental and Energy Sustainability Matters.

Year 2013 is taken as the reference year as it matches the entry into force of the new law regarding fiscal measures on energy sustainability issues. Following the enactment of this legislation, a set of fiscal charges should be considered in production and storage of high level radioactive waste. Since the existing legislation only contemplates today's Spanish situation with the Once-Through Cycle, a number of assumptions regarding taxation purposes are made in order to make the fiscal charges calculation as equitable as possible in both management options.

The study covers up to year 2028 as it is the last operational year of the two last Spanish nuclear power plants according to the nuclear power plants' timeline based on the legislation in force to date.

In the Twice-Through Cycle management strategy, the scenario assumed is one in which the entire nuclear park would start using MOX fuel from 2018 on, using conventional UOX fuel from 2013 until 2017 inclusive. The MOX fuel is obtained from reprocessing the spent UOX fuel stored to date (December 2012).

In the twice-through cycle strategy, no interim storage of used fuel is considered. The spent UOX and MOX fuels are sent integrally abroad, first to be used in the fabrication of MOX fuel to be burnt in Spanish nuclear plants, and then to sell the valuable materials (uranium and plutonium) on the international market, to avoid storing spent fuel in the CTS together with the vitrified and compacted high level waste coming from the reprocessed products, as its management in the CTS would become more expensive not being able to take advantage of the volume optimization achieved with the vitrified and compacted waste in the Twice-Through Cycle.

Our decision not to consider the cost of final disposal has been reinforced by the fact that up to this date, the Spanish research regarding the DGR has been paralyzed for almost two decades, leaving a complete uncertainty on the budget which this project would represent in the end of the Spanish case.

Once the corresponding calculations of both parts of the assessment are made, an evaluation of the management cost is performed with the purpose of determining the most economically competitive management cycle in the Spanish scenario with the hypotheses raised. The results are exposed in the study [15].

This paper focuses on one major point inside the second part of the study [15], which consists of analyzing the impact of a new Spanish law: the Environmental and Energy Sustainability Taxation Measures [16] which came into force at the beginning of 2013 .

\section{Spanish Scenario}

4.1. Legal Framework and Actors of Used Nuclear Fuel and Radioactive Waste Management in Spain. The activities implied by the "back-end of the nuclear fuel cycle" (management, storage, and disposal of the radioactive waste and used fuel) produced in Spain are performed by the public agency Empresa Nacional de Residuos Radiactivos, S.A (ENRESA). Their ordering and financing are detailed in a General Radioactive Waste Plan (VI Plan General de Residuos Radiactivos, PGRR.) approved by the Cabinet of Ministers. The Spanish government decision of the strategy to adopt regarding the management of the used nuclear fuel and ENRESA executes its policy. 
The regulatory framework in force in Spain that establishes that the costs of activities deriving from the management of radioactive wastes shall be financed by the waste producers. Until 2005, the financing of the costs was only through tariffs and therefore was paid by the final consumer; in 2005 a new tax changed this system as the Spanish utilities running nuclear plant started to contribute directly, and since 2009 , they are financing $100 \%$ of the back-end cost through taxes.

A complete different angle and objective pursue the Taxation Measures on Environmental and Energy Sustainability Matters, that we analyze in this article. Whereas the regulated part of tariffs paid by the utilities described above aims at covering the costs of the radioactive waste management, the law of Taxation Measures on Environmental and Energy Sustainability Matters introduces, among others, a new set of taxes on the production and the storage of radioactive waste and used fuel, that will not be used to finance any back-end cost, but will go to the Government general budget. These new fiscal charges are claimed by the utilities to represent such an additional burden, that it heavily impacts the cost and therefore the strategy of management of used fuel and radioactive waste in Spain. This paper aims at describing how and at comparing the economic impact of this law within the frame of the current Once-through policy to the one it could have been in the scenario of a Twice-through strategy.

\subsection{High-Level Radioactive Waste Management and the Span-} ish Centralised Temporary Storage (CTS) Project. At present, Spain's spent nuclear fuel is temporarily kept in the nuclear power plants' pools to eventually shift it to an interim storage facility called a Centralised Temporary Storage (CTS). The recent choice of site for the construction of the new CTS has been a relevant milestone for the nuclear industry in Spain. On December 30th of 2011, the Government finally chose Villar de Cañas, Cuenca, as the site to host this facility. This large nuclear waste warehouse will store from medium- to high-level radioactive waste [1].

Spain's CTS is currently in its design phase and is expected to be available for use in 2019. The construction of this new CTS is necessary regardless of the cycle option.

Technical reasons reside in the approaching saturation of the nuclear power plants' pools as well as in the need to safely keep the around $2000 \mathrm{~m}^{3}$ of future high-level radioactive waste that will be generated in the decommissioning of the Spanish NPP. Likewise, 68 caps of high level vitrified waste derived from part of the fuel from Vandellós I NP are currently kept in France and must return to Spain, as stated in the European Directive (Council Directive 2011/70/Euratom of 19 July 2011), that specifies that each nuclear country must take care of its own residues.

(From the security and economical point of view, a centralised location will always be more optimal and costefficient than having seven scattered sites with decentralized nuclear waste warehouses and multiple security systems, one for each Spanish NP.)
4.3. Past, Present, and Future Tendencies regarding LongTerm Spanish Waste Management. Spain's current position regarding nuclear waste management is to consider spent fuel as a highly-radioactive waste which must be ultimately disposed in a DGR, opting for the Open-Through Cycle. However, the possibility of reprocessing and recycling this spent fuel is not totally discarded and is even considered as a "potential alternative scenario" by the Spanish Radioactive Waste Management Plan "even though this option cannot be considered to be exclusively a question of waste management, but rather, and depending on the quantity to be reprocessed, it is a policy issue of energy supply" ( $6^{\circ}$ RWMP, C.II.1.3 Líneas estratégicas de acción). In fact, as mentioned before, in the past, part of the spent fuel from Vandellós I was reprocessed in a reprocessing plant in France and a smaller portion from Santa María de Garoña and José Cabrera NPs was sent to the UK for the same purpose.

Regarding long-term back-end strategy and final disposal (which stays out of the frame of our study), it is important to point out the fact that although the DGR is considered by the plan as the final destination of the Spanish nuclear waste, the research regarding this installation, which would be needed in some years' time, has been paralyzed since 1996, mainly due to the opposition of local populations, leaving an undefined future ahead and therefore offering the possibility of reconsidering the reprocessing option.

4.4. Taxation Measures Law on Environmental and Energy Sustainability Matters. One of the major reasons which may make the reprocessing option regain strength in the Spanish scenario is the recent Taxation Measures Law which came into force at the beginning of 2013. This law identifies the following tax rates linked to the nuclear waste.

(i) In the production of spent nuclear fuel as a result of nuclear power generation, the tax rate is 2190 $€ / \mathrm{kgHM}$

(ii) In the storage of spent fuel and radioactive waste, the tax rate will be $70 € / \mathrm{kgHM}$.

(iii) In the storage of medium to high level radioactive waste different from the spent, fuel the tax rate will be $30000 € / \mathrm{m}^{3}$.

The tax on production of spent fuel has to be paid by the utilities. It is calculated in each nuclear power plant, every time fuel assemblies are definitively taken out of the reactor after irradiation.

The tax on centralized storage of spent fuel and radioactive waste will have to be paid by ENRESA. The basis to calculate the fiscal charges will be the annual variation of the volume of spent fuel and waste stored in the CTS.

One of the aims of this paper is to establish whether those new taxes would affect differently the cost of used fuel and waste management, in case of choosing to recycle the Spanish used fuel instead of disposing it as final waste.

As a matter of fact, sending the used fuel elements to be recycled to a reprocessing plant in Europe would imply to evacuate the used fuel elements directly from the power plants to a foreign country and eliminate the need of 
TABLE 1: Cash flows for the year 2013 by type of tax and year and the total cash flows. Once-Through Cycle.

\begin{tabular}{llllllllllllllllllll}
\hline & 2013 & 2014 & 2015 & 2016 & 2017 & 2018 & 2019 & 2020 & 2021 & 2022 & 2023 & 2024 & 2025 & 2026 & 2027 & 2028 & $\begin{array}{c}\text { Total } \\
\left(\mathrm{M} €_{2013}\right)\end{array}$ \\
\hline $\begin{array}{l}\text { New UOX production } \\
\text { tax, } \\
\left(\mathrm{M} €_{2013}\right)\end{array}$ & 306,6 & 306,6 & 306,6 & 306,6 & 306,6 & 306,6 & 306,6 & 306,6 & 306,6 & 262,8 & 262,8 & 175,2 & 131,4 & 87,6 & 87,6 & 87,6 & 3854,4 \\
\hline $\begin{array}{l}\text { UOX storage tax, } \\
\left(\mathrm{M} €_{\text {2013 }}\right)\end{array}$ & 303,4 & 313,2 & 323,0 & 332,8 & 342,6 & 352,4 & 362,2 & 372,0 & 381,8 & 390,2 & 398,6 & 404,2 & 408,4 & 411,2 & 414,0 & 416,8 & 5926,9 \\
\hline
\end{tabular}

TABLE 2: Cash flows for the year 2013 by type of tax and year and the total cash flows. Twice-Through Cycle.

\begin{tabular}{lccccccccccccccccc}
\hline & 2013 & 2014 & 2015 & 2016 & 2017 & 2018 & 2019 & 2020 & 2021 & 2022 & 2023 & 2024 & 2025 & 2026 & 2027 & 2028 & $\begin{array}{c}\text { Total } \\
\left(\mathrm{M} €_{2013}\right)\end{array}$ \\
\hline $\begin{array}{l}\text { New UOX production } \\
\text { tax, }\left(\mathrm{M} €_{2013}\right)\end{array}$ & 306,6 & 306,6 & 306,6 & 306,6 & 306,6 & 204,4 & 204,4 & 204,4 & 204,4 & 175,2 & 175,2 & 116,8 & 87,6 & 58,4 & 58,4 & 58,4 & 3080,6 \\
\hline $\begin{array}{l}\text { RepU Sale } \\
\left(\mathrm{M} €_{2013}\right)\end{array}$ & $-16,9$ & $-16,9$ & $-16,9$ & $-16,9$ & $-16,9$ & $-11,2$ & $-11,2$ & $-11,2$ & $-11,2$ & $-9,6$ & $-9,6$ & $-6,4$ & $-4,8$ & $-3,2$ & $-3,2$ & $-167,9$ & -334 \\
\hline $\begin{array}{l}\text { Pu Sale } \\
\left(\mathrm{M} €_{2013}\right)\end{array}$ & $-28,8$ & $-28,8$ & $-28,8$ & $-28,8$ & $-28,8$ & $-19,2$ & $-19,2$ & $-19,2$ & $-19,2$ & $-16,5$ & $-16,5$ & -11 & $-8,2$ & $-5,5$ & $-5,5$ & $-287,3$ & $-571,6$ \\
\hline $\begin{array}{l}\text { HLW storage tax } \\
\left(\mathrm{M} €_{2013}\right)\end{array}$ & 0 & 0 & 0 & 0 & 0 & 0 & 3 & 3 & 3 & 3 & 2,6 & 2,6 & 1,7 & 1,3 & 0,9 & 1,7 & 22,9 \\
\hline $\begin{array}{l}\text { Spent MOX } \\
\text { production tax } \\
\left(\mathrm{M} €_{2013}\right)\end{array}$ & 0 & 0 & 0 & 0 & 0 & 102,2 & 102,2 & 102,2 & 102,2 & 87,6 & 87,6 & 58,4 & 43,8 & 29,2 & 29,2 & 29,2 & 773,8 \\
\hline
\end{tabular}

TABLE 3: Total taxes obtained for period 2013-2028 in each fuel management cycle.

\begin{tabular}{lcc}
\hline Once-Through Cycle & Twice-Through Cycle & $\% \Delta$ fiscal charges \\
\hline $9781,3 \mathrm{M} €_{2013}$ & $2971,7 \mathrm{M} €_{2013}$ & 229 \\
\hline
\end{tabular}

centralized storage of the fuel assemblies as such, necessary in the case of final disposal.

The centralized storage (CTS) would still be needed, but only to store residual waste generated by the reprocessing (vitrified and compacted). As a consequence, the tax would be paid on the high level waste stored in the CTS only and it would imply to postpone the payment of the tax on the interim storage until the day the residues come back to Spain.

4.5. Economic Aspects of the New Legislation Applied to the Once-Through Cycle and the Twice-Through Cycle. The comparative economic feasibility study performed for the two spent fuel management cycles covers the years from 2013, coinciding with the entry into force of the new law regarding fiscal measures, to 2028, the last operating year of the last two Spanish NPPs according to the nuclear power plants' timeline.

Since the law solely contemplates today's Spanish situation with the Once-Through Cycle, a number of assumptions regarding taxation purposes are posed for the Twice-Through Cycle option in order to make the fiscal charges calculation as equitable as possible in both management options.
Therefore, in the case of the Once-Through Cycle, the annual fiscal charges that must be taken into account are the ones mentioned in the law:

(i) on the one hand, a tax due to production of spent fuel from all nuclear power plants in operation during the years 2013-2028: $2190 € / \mathrm{kgHM}$,

(ii) on the other hand, a tax due to the storage of spent fuel, not forgetting to include the spent fuel stored prior to the year 2013: $70 € / \mathrm{kgHM}$.

In case the Twice-Through Cycle is implemented in Spain, the scenario assumed is one in which the entire nuclear park would start using MOX fuel from 2018 on, using conventional UOX fuel from 2013 until 2017 inclusive. The MOX fuel used is obtained from reprocessing the spent UOX fuel stored to date (December 2012). The annual fiscal charges assumed in this case are as follows.

(i) A tax due to production of both conventional UOX spent fuel and MOX spent fuel. In this management cycle, the fuel introduced in each reactor would be a combination of both types of fuel in the proportion of $1 / 3$ of MOX fuel elements and $2 / 3$ of UOX fuel elements. This tax rate has been assumed to be equal for both types of fuel: $2190 € / \mathrm{kgHM}$.

(ii) A tax due to the storage of vitrified and compacted high level waste coming from the reprocessed fuel: $30000 € / \mathrm{m}^{3}$. 
Differently from the Once-Through Cycle, the tax due to the storage of UOX spent fuel is not considered since the stock of spent fuel stored until 2012 is assumed to be sent to reprocessing in order to be used in the fabrication of the MOX that is burnt in the Spanish reactor until 2028, and the generated spent fuel during 2013-2028 is also assumed to be sent to a reprocessing plant in order to subsequently sell the recovered plutonium and the reprocessed uranium in the international market.

\section{Results}

The results [15] have shown that the whole Twice-Through Cycle is economically more expensive than the OnceThrough Cycle, and with the hypotheses raised in the TwiceThrough Cycle, the taxes related to the nuclear waste have such an impact that reverse the cost results making the total annual costs in this cycle lower than in the Once-Through Cycle.

Considering an annual discount rate of 7,6\% [2], the total fiscal charges to be paid during the period 2013-2028 in Open-Through Cycle are shown in Table 1 and the total cash flows for the Twice-Trough Cycle are shown in Table 2.

The huge difference between both cycles, summarized in the Table 3, is due to the substantial difference in the quantity, both in $\mathrm{kgHM}$ and volume, of nuclear waste produced and therefore needed to be stored. Also, the generated spent fuel during 2013-2028 which is assumed to be sold in the international market in the Twice-Through Cycle contributes to reduce the stock of material to be disposed of.

From all the above and taking into account both the fuel management cycle costs related to the processes and technology in each step of the cycle and the annual fiscal charges corresponding to each cycle, the calculations obtained in the study determine that the total annual costs turn out to be between 30\% (year 2013) and 146\% (year 2028) lower than in the Once-Through Cycle.

\section{Conclusions}

The main conclusion drawn from the economic assessment applied to the Spanish case is that the new legislation Taxation Measures Law on Environmental and Energy Sustainability Matters recently entered into force, January 1st 2013, which taxes the production and storage of radioactive waste and used fuel will have an important impact on the cost of backend management in Spain considered in the medium term. What we found out, according to our calculations, is that the taxes would be significantly lower in case of sending Spanish used fuel to be reprocessed (Twice-through cycle strategy) instead of storing it (once-through cycle strategy).

Regardless of the existing legislation, the current technology associated with the Twice-Through Cycle has a higher cost. However, a difference of around $10-15 \%$ between the management costs of both cycles is considered to be acceptable noting the degree of uncertainty involved, as well as the exclusion of the costs related to the geological repository for both alternatives. As an additional comment, when taking in account relation to DGR costs, what is well known is that a Twice-Through Cycle would need a significantly smaller DGR than the one that would be needed to store the spent fuel in a Once-Through cycle.

When considering the impact of the taxes on production and centralized storage of used fuel, the difference between the current once-through and the Twice-through cycle strategy may change the situation and at the minimum raise interest among the Spanish utilities to consider opening a new critical reflection on what to do with the used fuel their nuclear power plants currently generates.

Furthermore, from the results mentioned above it can be verified, as an additional conclusion, that energy policies with either premiums or fiscal charges can have an important impact on a specific technology.

\section{Conflict of Interests}

The authors declare that there is no conflict of interests regarding the publication of this paper.

\section{References}

[1] Spanish Nuclear Industry Forum, "Nuclear Results and Perspectives. 2011, a year of nuclear energy," Annual Report, 2011.

[2] The Future of Nuclear Power: an interdisciplinary MIT study, Massachusetts Institute of Technology, 2003.

[3] G. de Roo and J. E. Parsons, "A methodology for calculating the levelized cost of electricity in nuclear power systems with fuel recycling," Energy Economics, vol. 33, no. 5, pp. 826-839, 2011.

[4] BCG, Economic Assessment of Used Nuclear Fuel Management in the United States, 2006.

[5] OECD/NEA, The Economics of the Nuclear Fuel Cycle, OECD, Paris, France, 1994.

[6] B. H. Park, F. Gao, E.-H. Kwon, and W. I. Ko, "Comparative study of different nuclear fuel cycle options: quantitative analysis on material flow," Energy Policy, vol. 39, no. 11, pp. 6916-6924, 2011.

[7] L. B. Silverio and W. D. Q. Lamas, "An analysis of development and research on spent nuclear fuel reprocessing," Energy Policy, vol. 39, no. 1, pp. 281-289, 2011.

[8] Direct Disposal of Spent Nuclear Fuel, Harvard Kennedy School, Project on Managing the Atom.

[9] T. P. Lagus, "Reprocessing of spent nuclear fuel: a policy analysis," Journal of Engineering and Public Policy, vol. 9, pp. 127, 2005.

[10] W. Ko and F. Gao, "Economic analysis of different nuclear fuel cycle options," Science and Technology of Nuclear Installations, vol. 2012, Article ID 293467, 10 pages, 2012.

[11] S. Widder, "Benefits and concerns of a closed nuclear fuel cycle," Journal of Renewable and Sustainable Energy, vol. 2, no. 6, Article ID 062801, 2010.

[12] E. A. Schneider, M. R. Deinert, and K. B. Cady, "Cost analysis of the US spent nuclear fuel reprocessing facility," Energy Economics, vol. 31, no. 5, pp. 627-634, 2009.

[13] G. D. Recktenwald and M. R. Deinert, "Cost probability analysis of reprocessing spent nuclear fuel in the US," Energy Economics, vol. 34, pp. 1873-1881, 2012.

[14] B. Y. Moratilla Soria, M. U. Mas, M. Estadieu, A. V. Lejarreta, and D. Echevarria-López, "Recycling versus long-term storage 
of nuclear fuel: economic factors," Science and Technology of Nuclear Installations, vol. 2013, Article ID 417048, 7 pages, 2013.

[15] Spent Nuclear Fuel Management, "Recycling vs. direct disposal of spent nuclear fuel. Spanish study case," 2013, http://www .iit.upcomillas.es/pfc/resumenes/519a5eb8a8a33.pdf.

[16] Proyecto de Ley de medidas fiscales para la sostenibilidad energética. (121/000025), 2013. 


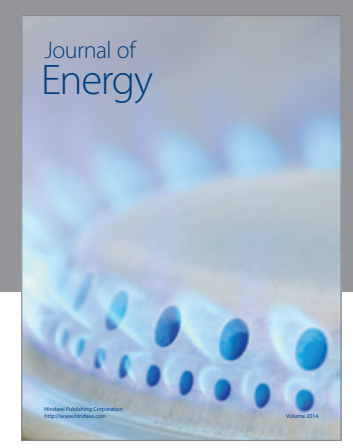

Journal of

Industrial Engineering
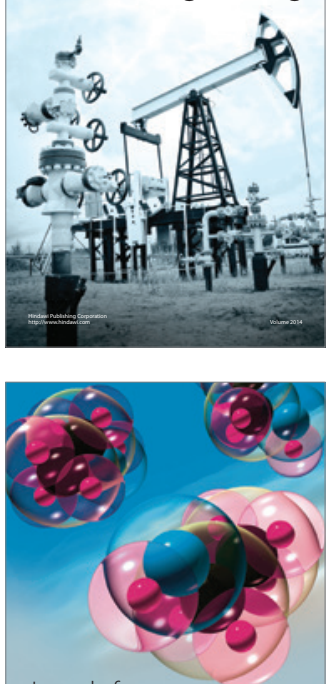

Fuels
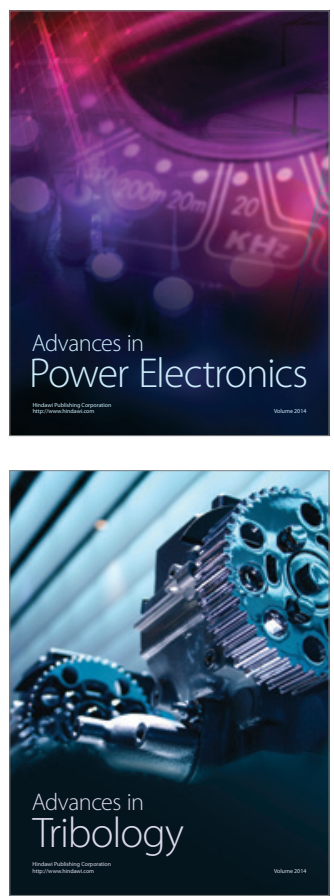

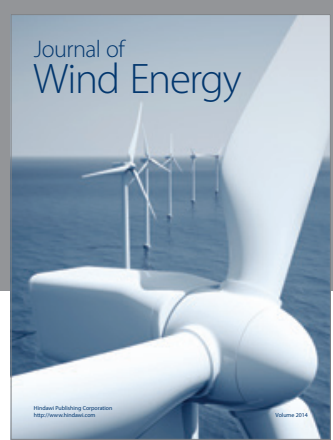

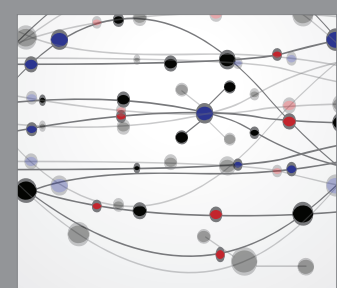

The Scientific World Journal

Submit your manuscripts at http://www.hindawi.com

Journal of

Structures
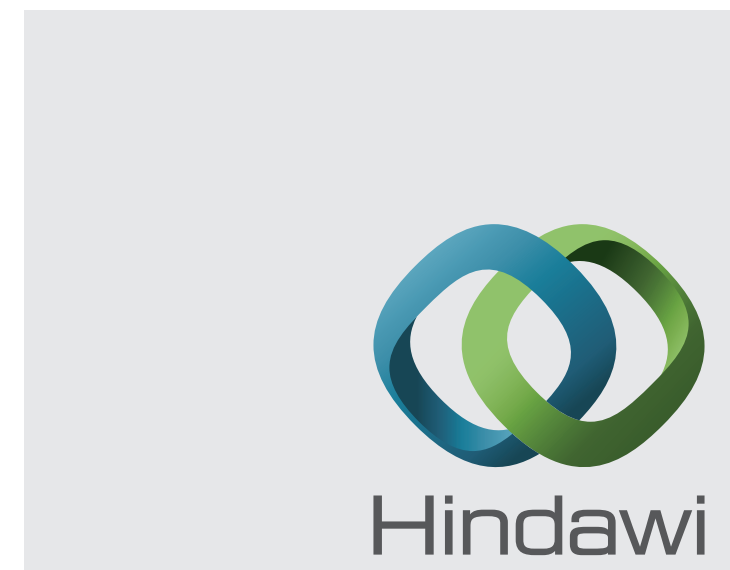

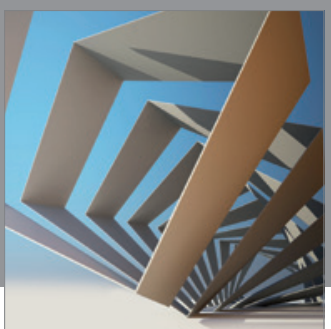

Rotating

Machinery
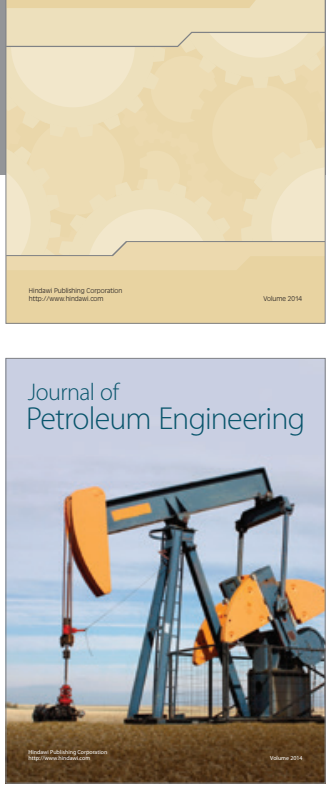

Journal of

Solar Energy
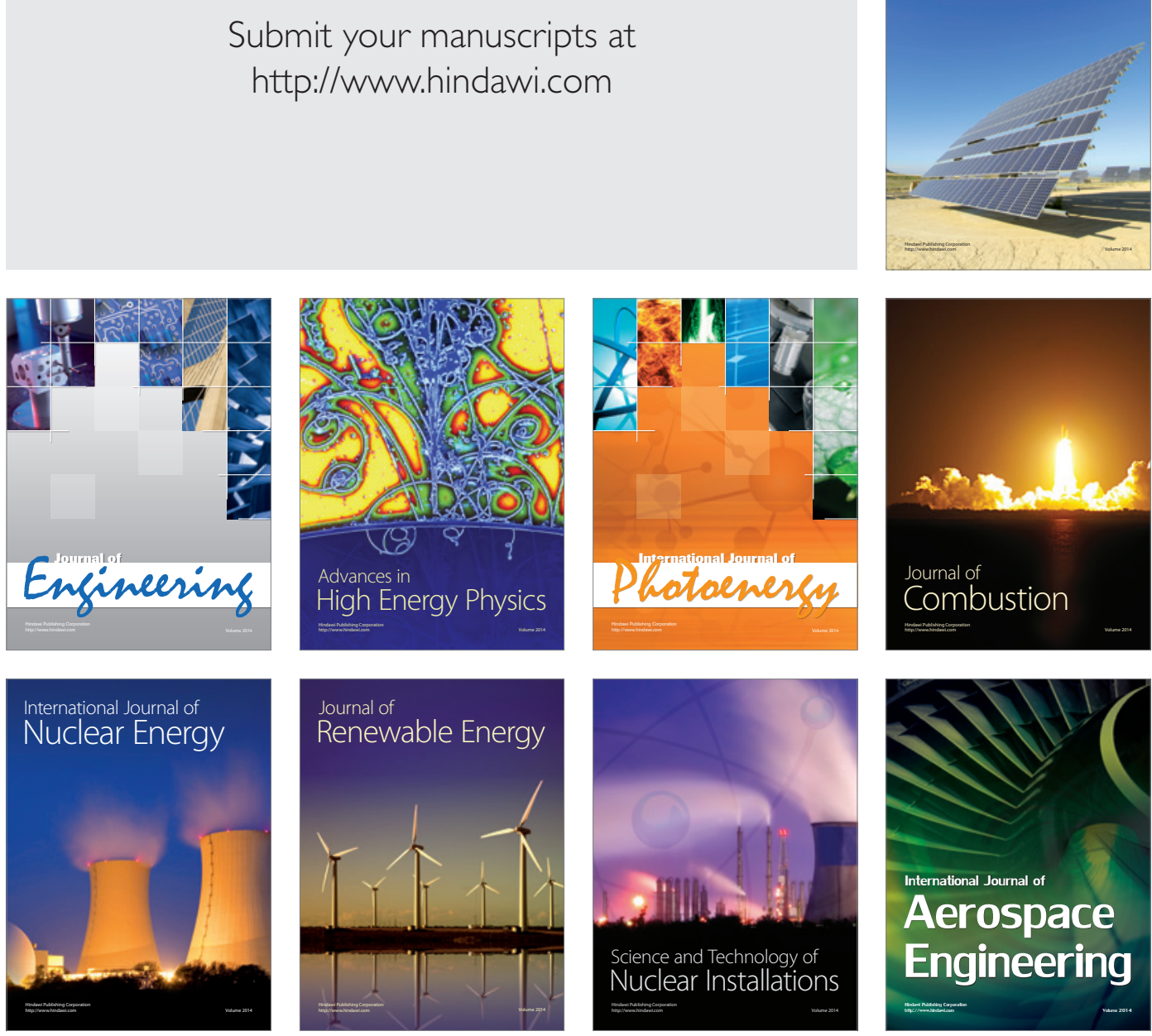